\title{
INSTITUIÇÃO ASSISTENCIAL E CIDADANIA
}

Regina Panceri*

SÍNTESE - O presente artigo visa destacar como se instaurou o processo de construção da cidadania junto ao jovem trabalhador, no periodo de 1971 a 1994, através de práticas assistenciais operacionalizadas pela instituição PROMENOR, possibilitando a formação e a inserção desses jovens no espaço social florianopolitano. Tal investigação partiu do pressuposto de que a descontinuidade verificada, tanto na trajetória da Instituiçäo PROMENOR quanto nas possibilidades de construção da cidadania, junto ao jovem trabalhador, tem-se articulado de forma conflitiva e/ou interativa com à dinâmica estrutural dos campos econômico, político e social, com base em relações de disputa, no decorrer do tempo.'
ABSTRACT - The present article aims to point out how the citizenship formation process of the young worker has been established, in the period comprised between 1971 and 1994, through assistance practices operationalized by the PROMENOR institution. This process has allowed the education and inclusion of this young people in the social space of Florianópolis.

\section{Introdução}

Para compreender mais especificamente como se instaurou o processo de construção da cidadania, através de práticas educativas e assistenciais operacionalizadas pela instituição PROMENOR, junto ao jovem trabalhador, optou-se por realizar a reconstituição histórica da referida instituição, articulando essa trajetória à dinâmica estrutural do campo do poder.

A operacionalização das principais dimensões e pressupostos relativos ao tema em análise foi definida, basicamente, a partir das seguintes concepções:

1 - o objeto de pesquisa é construído, tornando-se necessário transformar o objeto social em objeto científico;

* Mestre em Serviço Social pela Pontifícia Universidade Católica do Rio Grande do Sul - PUCRS

1 A construção desse objeto de estudo faz parte da dissertação de mestrado intitulada "Instituição Assistencial e Cidadania", e está articulada à linha de pesquisa: "Formação, Trabalho e Instituição", coordenada pela prof. Julieta Beatriz Ramos Desaulniers.

\begin{tabular}{|l|l|l|l|l|l|}
\hline VERITAS & Porto Alegre & v. 42 & $\mathrm{n}^{2} 2$ & Junho 1997 & p. 205-216 \\
\hline
\end{tabular}


2 - a articulação entre teoria, método e dados é fundamental para atribuir um caráter de cientificidade ao fato estudado;

3 - o estabelecimento de um corpo de hipóteses (juízos sintéticos a priori) e a definição específica de um referencial teórico são essenciais para ultrapassar um mero intuitivismo em relação ao objeto, optando-se pela utilização de aspectos da abordagem de Bourdieu, Bachelard, Chapoulie, Petitat, Stroobonts e outros.

O referencial citado contribuiu para analisar o processo de formação e de construção da cidadania na PROMENOR - um processo globalizante que facilitou a instauração de um novo habitus junto ao jovem trabalhador - como também captar o sistema de relações construído nessa instituição, representado pela dinâmica estrutural do campo assistencial em confronto com os demais campos do poder.

Ao reconstituir historicamente as ações que deram origem à instituição PROMENOR, pretende-se destacar as lutas de poder (conflitivas e/ou interativas), travadas entre os vários campos do espaço social e a repercussão das práticas educativas implementadas pelo assistente social, assim como o papel exercido pelas dimensões institucionais no processo de formação e de construção da cidadania junto ao jovem trabalhador, considerando que as rupturas ocorridas no campo do poder, provocam mudanças nas práticas sociais, econômicas e políticas.

\section{As dimensões institucionais: possibilidades e limites à construção da cidadania}

As instituições surgem a partir de determinadas demandas e são instâncias fundamentais da sociedade por estarem pautadas em normas, padrões, leis, valores e práticas que regem as relaçōes entre os homens, exercendo papel significativo junto a vários setores sociais. São complexas por serem resultantes de um conjunto de relações sociais, as quais se instauram a partir de uma base material e de gestão, bem como através das práticas, dos interesses e das categorias de interpretação dos diversos grupos de agentes (Chapoulie, 1994).

A Sociedade Promocional do Menor Trabalhador - PROMENOR, fundada em 1971, como uma organização não governamental (ONG) foi efetivamente estruturada a partir da problemática das crianças pobres, desassistidas pelo poder público e que faziam da rua seu local de sobrevivência, mobilizando os representantes do governo e da sociedade florianopolitana, que já se ressentiam com os problemas sociais advindos da ordem econômica e política. As estratégias de implantação articularam-se em torno de um sistema de relações que envolvia os poderes locais e estaduais e, posteriormente, legitimada cada vez mais pela sociedade civil.

No que se refere às bases materiais e de gestão, a instituição passou por três momentos significativos:

1. de 1971-1974, deu-se a implantação e estruturação da instituição, sendo que a preocupação com a base material era uma constante e para conquistar espaço junto aos principais setores da sociedade, a diretoria da PROMENOR mobilizou a elite florianopolitana e catarinense no sentido de obter o apoio necessário para iniciar a construção da sede, a fim de ampliar o atendimento às crianças e adolescentes. A instituição recebeu todo o respaldo político e social da Primeira Dama do 
Estado, o que significou a entrada constante de recursos financeiros e de outros tipos de apoio. As práticas educativas implementadas privilegiavam o agir prático, estabelecendo relações de proximidade com os usuários, distanciando-se da trama de relações sociais, não havendo uma relação teórico/prática consistente. A gestão estava pautada num sistema baseado na hegemonia e rígida hierarquia das decisões e as consequiências daí surgidas foram, basicamente, provocadas a partir das desigualdades criadas pelos agentes sociais em suas contínuas relações de disputa e de condições de poder para mantê-las, uma vez que o poder só se faz e se exerce através de relações sociais determinadas. Bourdieu concebe as relações sociais como relações de poder, visto que produzem o sistema de dominação interiorizado pelos agentes sociais. (apud Ortiz, 1983, p. 26)

2. de 1975-1977, com o término do mandato do então Governo Estadual, houve rupturas na PROMENOR, o que acarretou um grande corte de recursos e a conseqüente dificuldade para a manutenção e sustentação da Instituição. A diretoria foi rearticulada e rompeu-se a hegemonia e a tomada de posição interativa, até então existentes no corpo administrativo institucional. Embora a nova diretoria se mobilizasse para arrecadar fundos, os gastos superaram o saldo e diante da possibilidade da Instituição ser extinta, buscou-se apoio junto à Irmandade do Divino Espírito Santo - IDES, uma instituição filantrópica, civil que já mantinha outros dois programas, um especificamente com meninas órfãs e um jardim de infância. O assistente social atuava como mediador para adaptar, ajustar e controlar, tendo pouca autonomia técnica, o que limitava o exercício da cidadania dos usuários.

3. de 1977-1994, ocorreram inúmeras mudanças e procedeu-se a uma descentralização administrativa, reformas no espaço físico, dando-se continuidade ao encaminhamento de adolescentes ao mercado de trabalho, na função de officeboys/girls, aumentando consideravelmente o número de convênios com empresas públicas e privadas. Formalizaram-se alguns convênios com o Estado para a manutenção dos programas e outros foram rompidos, na medida que se observava interferência e ingerência externa. Os assistentes sociais, nesse período, conseguiram regulamentar e dinamizar as práticas educativas, ampliando consideravelmente a participação dos usuários e o exercício da cidadania. Na medida que os assistentes sociais passaram a ter mais autonomia e competência técnica, tiveram reconhecimento de sua prática, possibilitando, com isso, a expansão e ampliação do seu trabalho e compreenderam como as relações de poder estabelecidas facilitam a reorientação das políticas institucionais, bem como, a redefinição das práticas educativas e assistenciais.

No que concerne à definição de papéis, funções e competências, pode-se inferir que, na instituição, estas eram a priori fixadas e estabelecidas de acordo com a quantidade e qualidade de capital (social, cultural, econômico, simbólico e político) de cada agente. O que acarreta várias consequiências e, como assinala Bourdieu (1990, p.154), "os agentes estão distribuídos no espaço social global, na primeira dimensão de acordo com o volume global de capital que eles possuem sob diferentes espécies, e na segunda dimensão, de acordo com a estrutura de seu 
capital [...]". Acrescente-se, ainda, que a capacidade do agente intervir depende estreitamente da posição ocupada no espaço social.

Como se pode observar, a atuação do assistente social na PROMENOR esteve presente desde o início, sofrendo alterações no decorrer do tempo e segundo Iamamotto (1992, p. 41), "nas instituições cujos programas principais se enquadram no campo social, mais precisamente da assistência, o assistente social tende a ocupar postos principais na hierarquia institucional", justamente por possuir um conhecimento técnico específico que lhe possibilita ter acesso à quase globalidade das esferas da vida cotidiana dos usuários. Além da atuação formadora, o assistente social opera com recursos institucionais para a prestação de serviços, racionalizando, administrando e controlando sua distribuição, visando, com isso, a um melhor funcionamento. Seu objetivo é transformar a maneira de ver, de agir, de se comportar e de sentir dos indivíduos em sua inserção na sociedade e como integrante do conjunto de atores institucionais, faz a instituição através de sua prática.

Na PROMENOR, a normatização das práticas educativas pelo assistente social visava estabelecer a regularidade das condutas, bem como a incorporação de determinados comportamentos por parte dos agentes integrantes do espaço social, constituindo-se num agente mediador na reestruturação do habitus. Assim, a noção de poder está associada à de habitus e no interior do campo luta-se para impor uma vontade, uma visão de mundo. Entretanto, a atuação do assistente social dependerá das relações de poder travadas entre os diferentes agentes que interagem no campo institucional e da direção politica adotada pelo profissional. 0 produto de sua ação, portanto, deve ser entendido também como produto das inter-relações entre os demais agentes e atores.

É importante salientar, que cada assistente social deixou a sua marca na Instituição, impondo uma maneira de ser, uma tendência, uma propensão, uma inclinação constitutiva de seu habitus e do capital cultural e simbólico acumulado, o qual só tem sentido em uma dada relação. (Bourdieu, 1983, p. 66)

Assim, a descontinuidade ocorrida na trajetónia da PROMENOR, as mudanças institucionais instauradas em função das alterações no cenário sócio-político nacional e estadual e as tomadas de posição conflitivas ocorridas entre os agentes envolvidos, repercutiram diretamente nas práticas desenvolvidas pelos diferentes setores sociais, bem como no interior da Instituição, acarretando um reordenamento nos programas realizados junto às crianças e adolescentes atendidos, acirrando a luta pela manutenção da PROMENOR.

Pode-se, então, dizer que essa instituição manteve-se como um contexto estruturado porque os agentes que a constituiam tinham um interesse em comum, o de fortalecer e garantir a própria existência da instituição enquanto uma esfera importante do campo assistencial, associada ao campo do poder.

O espaço institucional ficou marcado pela forma como se estabeleceram as relações de disputa entre os agentes, sendo que o processo de formação, de construção de saberes e de orientações no exercício da cidadania assumiram configurações diferenciadas no decorrer do tempo. Tais relações somente poderão ser compreendidas na medida que se levar em conta a posição que estes agentes detinham no espaço social, bem como a representação, percepção e apreciação 
que possuíam sobre a realidade social. A seguir, demonstrar-se-á como as práticas realizadas na PROMENOR, visando a construção da cidadania, foram influenciadas pela forma como desencadeou-se o processo político brasileiro, repercutindo na concepção de trabalho instaurada, a qual oscilou entre a concepção de trabalho/profissão e trabalho/cidadania. Infere-se, ainda, que a ampliação dos espaços democráticos repercutem nas práticas assistenciais institucionais, tendendo a reforçar o exercício da cidadania.

\section{O processo de formação e a instauração de saberes}

A realidade social é produzida, quase em sua totalidade, em contextos institucionais, nos quais o aspecto formativo está sempre presente. As instituições, por sua vez, são criadas com objetivos especificos pelos seus dirigentes e organizadores e estão destinadas a oferecer um único modelo de formação, a uma clientela subscrita, de acordo com os propósitos que visa a atingir.

Os processos de formação contribuem para a instauração da cidadania quando oportunizam aos individuos, grupos e classes, que lutem pela conquista e ampliação de direitos, assim como, pelo cumprimento de seus respectivos deveres, visando a garantia e a conquista de poder em uma dada realidade social.

Na PROMENOR, inicialmente, o projeto pedagógico implementado não fomentou um processo de ação e de inserção ativa dos jovens no contexto, limitando sensivelmente o exercício da cidadania. Os agentes não tinham consciência de que essa prática constituía-se num processo de formação, preocupados que estavam com 0 atendimento das necessidades básicas das crianças e adolescentes. Observa-se que a formação proposta pautava-se no discurso paternalista, tendo como princípios embasadores o trabalho propriamente ocupacional, visando produzir trabalhadores, em consonância com a política de bem-estar do menor (PNBEM), a qual propunha a ocupação controlada do tempo e do espaço, como um meio de aprendizado e de integração social, constituindo-se numa das principais estratégias para prevenir a marginalização infantil.

Partindo do postulado proposto por essa política, a formação profissionalizante passou a ser regra, predominando a concepção de trabalho/profissão, pautada no saber-fazer e fortalecida pelo ensinamento de alguns ofícios (pouco expressivos no mercado de trabalho). As habilidades comportamentais e manuais eram salientadas, em detrimento das questões técnicas do trabalho, através de práticas pedagógicas, pautadas em relações hierarquizadas, possibilitando a reestruturação do habitus, o qual é definido como "um sistema de disposições duráveis e transponíveis, estruturas estruturadas, predispostas a funcionar como estruturas estruturantes" (Bourdieu, 1980, p. 88). Enquanto disposição para a prática, constitui o fundamental objetivo de condutas regulares.

O educando, por sua vez, assumia uma postura submissa, obediente, cordata e a forma incisiva como se trataram inicialmente as questões relativas à disciplina, ao comportamento do educando e ao funcionamento da Instituição revela, nitidamente, que esse processo pretendia envolver o educando em sua totalidade e, assim, instaurar um novo sistema de disposições que resultasse numa mudança de habitus, superando gradativamente os princípios e os valores já incorporados e 
apresentados pelas crianças e adolescentes, "por meio de uma ação pedagógica que visa inculcar, o mais profundamente e durável possível, uma atitude, através de comportamentos precisos e singulares" (Bourdieu apud Desaulniers, 1996, p. 251), considerando que as disposições definidoras do habitus são incorporadas, em sua maioria, na infância.

Visando obter comportamentos homogêneos e precisos, a Instituição estabeleceu normas, regras e limites e na medida que eram descumpridos utilizava-se do recurso da punição. Os horários e atividades desenvolvidas diariamente eram rigidamente controlados pelo monitor e demais profissionais que atuavam junto às crianças e adolescentes. A seleção da clientela seguia critérios preestabelecidos, estipulando-se o tempo de permanência dos usuários na Instituição. Esse conjunto de dispositivos, previstos no Regulamento Interno, tornava possível a ocupação controlada do tempo, definindo a posição ocupada pelo adolescente no contexto da PROMENOR. Desta forma, a concepção de regra estava pautada num "conjunto de regularidades objetivas impostas a todos aqueles que fazem parte do contexto institucional, reunindo as condições sociais para sua eficácia, uma vez que a regra não é eficaz por si mesma". Portanto, todo campo é regido por regras e leis de funcionamento e para, que funcione, os agentes devem estar predispostos a aceitá-las e ser dotados de capacidade para entendê-las (Bourdieu, 1990, 79 e 96).

Posteriormente, com as mudanças politicas ocorridas, foi se instaurando uma nova concepção de trabalho, associada à cidadania, ao direito, a inserção crítica no contexto social, alterando-se conseqüentemente, o processo de formação do jovem trabalhador, recuperando-se o sentido do agir humano e do trabalho como um espaço de construção das relações sociais, de aprendizado, capacitação e independência. Portanto, é indispensável apreender as interações entre a política e a instituição e isto exige analisar, em sua singularidade, as conjunturas históricas, levando-se em conta as suas dimensões politicas, financeiras, culturais e institucionais (Chapoulie, 1994, p. 39).

Para o jovem, o espaço profissional passou a ser também uma oportunidade de confrontar as relações entre o mundo do trabalho e a educação. Dessa maneira, formar para a cidadania, através do trabalho e/ou da escola, significa formar o educando para viver numa sociedade de classes, seguindo padrões de uma cultura política, em que a troca de experiências, o diálogo, a construção de relações sociais, da organização e da participação vão se constituindo. Ao que parece, a estruturação desses elementos depende de fatores conjunturais, e este tipo de fenômeno não escapou à observação de Chapoulie (1994, p. 46-7), uma vez que para ele

as evoluções das probabilidades de acesso a determinado posto de trabalho ou a determinado nivel de ensino conforme a origem de classe constituem-se em fenômenos essencialmente conjunturais, determinados pelo jogo entre os diferentes tipos de determinações.

Pode-se dizer, que a formação desenvolvida inicialmente não estava voltada ao exercício de uma reflexão e inserção crítica, associando-se bastante bem aos interesses do sistema político autoritário, especialmente dos anos 70, época também em que a terceirização passou a ser implementada no Brasil. Assim, a inauguração da PROMENOR, o seu funcionamento quase imediato pautado na concep- 
ção de trabalho/profissão, em que a atividade laborativa era uma forma de ocupar o tempo, garantir a sobrevivência e prevenir uma suposta "marginalização", foi uma resposta sincronizada da instituição a esse momento da realidade brasileira e florianopolitana.

Esse processo visava a criar e desenvolver uma mudança de habitus e, em toda a sua trajetória, esteve articulado à dinâmica capital-trabalho, constituída dentro de um poder elitista.

Certamente, a mudança na rotina diária, a ampliação das relações, o redimensionamento da ocupação do tempo, o encontro de um novo sentido para a vida que foram construídos no decorrer da permanência dos jovens no programa, acabaram por instaurar uma mudança de habitus, uma vez que a constituição do habitus depende de várias circunstâncias do próprio campo: sua autonomia, posição ocupada pelo agente no campo e o grau de institucionalização do posto. 0 habitus exprime sempre a posição social em que foi constituído.

Conclui-se, então, que essa obra assistencial foi definida por um conjunto de relações, afirmando-se através da prestação de serviços, a partir das demandas do contexto social florianopolitano, reforçando o princípio que definiu sua gênese. Observa-se, também, que o processo de formação foi implantado verticalmente, com o objetivo de assegurar competência individual, excluindo a participação social, especialmente na metade da primeira década.

Em função das mudanças conjunturais, tecnológicas, políticas e jurídicas, foi se relativizando a concepção de trabalho/profissão e trabalho/cidadania, permitindo a existência de ambas, uma vez que a garantia de trabalho somente ocorre quando articulada ao mercado. Esta ambigüidade há que ser considerada especialmente neste momento em que se discute a introdução de novas tecnologias e a qualidade total simultaneamente com a construção da cidadania.

O futuro e a ordenação do espaço institucional e dos seus agentes vão se configurando de acordo com o modelo pedagógico implantado, das práticas dos diferentes agentes que interagem nesse espaço e do clima institucional que se pretenda, projetando-se o futuro desse espaço e dos seus agentes, possibilitando não somente a articulação de saberes, mas, sobretudo, a relativização entre saberfazer, saber-ser.

Por essa razão, o processo de formação globalizante resulta na combinação e interiorização de inúmeros saberes (tácitos, formais, informais) que, articulados, resultam em certas competências.

\section{Construção da cidadania e do saber-ser}

Os saberes que constituíram a formação desses educandos, nessas duas últimas décadas, apresentaram vários elementos que qualificaram positivamente sua trajetória. Entretanto, os jovens, ao ingressarem no mercado de trabalho, não estavam suficientemente preparados para essa realidade e depararam-se com inúmeras dificuldades, que, para serem superadas, exigiram a utilização adequada de todos os conhecimentos tácitos e informais adquiridos.

Nesta perspectiva de aprendizado, a médio e longo prazo, em que se produzem mudanças comportamentais entre outras, é interessante registrar a relação 
que Chapoulie estabelece entre tempo e aprendizado: “é necessário um período relativamente longo para que os problemas que qualquer transformação institucional produz sejam definidos e reconhecidos como tais, dentro e fora da instituição. E um prazo mais longo para que o efeito dessas transformações, sobre os "produtos", que são os educandos, possam aparecer" (1994, p. 38).

A inserção num contexto amplo, diversificado, complexo, propicia uma diversidade de saberes, permitindo ao jovem checar sua capacidade, habilidades e comportamentos, ampliando as chances de se instaurarem novas perspectivas e o saber-ser competente, reforçando assim, junto a esses jovens, a constituição da cidadania.

A competência, portanto, foi construída através dos vários desafios que os jovens precisaram enfrentar na Instituição e, especialmente, nos postos de trabalho, sendo obrigados a recorrer aos vários conhecimentos que estavam obtendo em sua formação, confirmando-se o postulado de que a "competência é mais saber-ser do que saber-fazer, porque trabalhador competente é aquele que sabe utilizar todos os seus conhecimentos nas mais diversas situações encontradas no seu posto de trabalho, integrando, de maneira eficaz, os conhecimentos sobre os objetos de ação" (Desaulniers, 1993, p. 34).

Para ilustrar apresenta-se como depoimento:

"Tive um crescimento de $200 \%$. Quando eu estava como office-boy aprendi a lidar com o público. A gente aprende a parte burocrática interna e extema; como funciona o sistema bancário. Depois os cursos foram fundamentais. Nada foi jogado fora" (ex-usuário).

Pode-se dizer que todos os saberes são absorvidos enquanto se exerce uma profissão. O desafio, pois, está na integração dos saberes tácitos, formais e informais que, associados, facilitam a descoberta de novas possibilidades de ação, auxiliando o educando a conceber uma nova maneira de ver o mundo, as pessoas e as relações.

Por outro lado, há que se considerar, também, que a oferta de emprego está bastante restrita para a demanda existente, não havendo lugar para todos, permanecendo a distância entre a explicitação constitucional dos direitos e sua efetivação na prática. A busca de pleno emprego é um princípio que se opõe às políticas e, desta forma, os mais informados e habilitados tecnicamente possuem maiores chances de opção e de inserção no mercado formal de trabalho. Entretanto, quanto mais estiverem relativizadas as relações entre o saber e o saber-fazer, maiores são as possibilidades de ampliar a construção de competência, especialmente, quando se concebe a formação como o conjunto da vida, da totalidade das relações humanas, e não mais somente voltada à questão do trabalho, da produção e do poder (Empson, 1986, p. 100).

Assim sendo, é importante enfatizar que "as novas exigências impostas à qualificação profissional demandam conteúdos relativos à ordem social, podendo ser adquiridos nos diversos espaços e tempos vividos pelo indivíduo". (Desaulniers,1993, p. 34).

Considerando-se o exposto, supõe-se que, na PROMENOR, a cidadania tem sido construída e reforçada através da interação do jovem trabalhador com as várias esferas da sociedade (familia, trabalho, escola, contexto social) as quais propiciam 
uma diversidade de fontes de obtenção de saberes, ampliando-se as chances de se instaurar o saber-ser competente, confórme ver-se-á no próximo item.

\section{Fontes de obtenção de saberes}

O conhecimento intelectual é um dos pressupostos na formação do cidadão, entretanto, não se pode negar o domínio de outros saberes, que, quando incorporados, permitem a consciência crítica, possibilitando a conquista da cidadania, ao mesmo tempo que fortalecem a competência do sujeito junto às várias atividades que venha a empreender. $\mathrm{O}$ saber, enquanto fenômeno que se constitui historicamente, recebe influências dos vários setores e poderes da sociedade, assumindo, portanto, configurações diferenciadas ao longo de sua constituição.

A conjuntura contemporânea e tecnológica coloca como principal objetivo da educação a criação de homens que sejam capazes de inovar. Como através da educação também se qualifica a mão-de-obra, hoje, a tônica está na integração da formação geral e profissional, ampla e multilateral. Por outro lado, sabe-se que um número crescente de instâncias de produção/difusão do saber escapam ao alcance da escola, como a formação na empresa, informatização, meios de comunicação, além da familia, igreja e outros. É importante considerar os processos informais de apropriação dos saberes, que contribuem para outros modos de conhecimento.

Atualmente, com a utilização de novas tecnologias, novas formas de organização de trabalho são desenvolvidas, exigindo do trabalhador maior comunicação, autonomia, iniciativa, criatividade, ações em equipe, participação, predominando a multiqualificação. Portanto, não basta mais saber-fazer, é preciso saber utilizar e transferir todos os conhecimentos obtidos no cotidiano e nas diferentes esferas para o ambiente de trabalho e vice-versa. Esta competência se traduz no saberser, conforme pode-se observar pelo depoimento de um ex-usuário:

\footnotetext{
"Hoje sou o que sou porque corri atrás do que queria. Trabalhei com troca de dólar, fui vendedor ambulante, garçom, office-boy [...] A gente precisa deixar de ser infantil; vai lendo, se informando, ouvindo comentários, convivendo com pessoas mais velhas. Fiz curso de computação, de atendimento ao público e datilografia [...]. Tudo isso se soma. Se não buscasse, não teria nada, profissionalmente [...]".
}

Como a família e a escola, o trabalho também é um espaço de relações sociais, de construção do coletivo e de transformação. É uma atividade desenvolvida com uma finalidade, e toda finalidade para ser atingida pressupõe determinado conhecimento. Exige, portanto, uma atitude do sujeito em face do objetivo que pretenda alcançar. Se, no trabalho há uma intencionalidade, esta pressupõe a existência da vontade, do esforço e da disciplina, estabelecendo um certo tipo de comportamento.

Os jovens entrevistados explicitaram que, após a entrada no trabalho, ocorreram mudanças em vários níveis de seu viver: pessoal, na família, no cuidado com bens públicos, na maneira de ver, agir e pensar, de se relacionar com os amigos, tornando-se pessoas mais determinadas, mais cidadãs.

Assim, em função de uma constante recomposição dos saberes exigidos pelo mundo do trabalho, é que se impõe, como necessidade, um processo de formação que possibilite o desenvolvimento mais amplo das inúmeras dimensões do indivi- 
duo e a participação ativa do mesmo na própria f́rmação, motivando-o a fazer escolhas.

Por isso, as possibilidades oferecidas por um processo de formação precisam estar organizadas no sentido de expor o educando a ações e experiências ligadas a todos os tipos de saberes. (Grof, 1993, p.11) afirma que "não há idéia ou sistema de pensamento, por mais antigo ou aparentemente absurdo, que não possa aumentar nossos conhecimentos".

Na PROMENOR tentou-se viabilizar um processo de integração gradual e contínua dos conhecimentos formais, específicos e informais, de hábitos e atitudes e de valores éticos, alargando o horizonte dos educandos, oportunizando-lhes conquistar mais espaços enquanto cidadãos. Desse modo, o processo de formação e de obtenção de saberes deu-se de forma descontínua e diferenciada de acordo com a realidade vivida pelo educando. Entretanto, todos os saberes obtidos na familia, na escola, no trabalho, nas relações interpessoais, na vida, na PROMENOR, no cotidiano foram importantes. Cada esfera contribuiu para gerar mais saber, somando-se progressivamente no processo de formação, assumindo uma característica globalizante. Os saberes foram adquirindo significação e utilidade, oportunizando o exercício da cidadania e a conquista de certas competências, permitindo-lhes atuar tanto no contexto de trabalho, quanto na sociedade em que vivem. Assim, a qualificação social (saber-ser) tende a ocupar, cada vez mais, o lugar da qualificação profissional (saber-fazer), sendo fundamental a participação ativa do individuo, a qual se caracteriza por um movimento de " auto fazer-se" permeado por relações que fazem parte das pessoas e contextos reais.

No processo de formação, há que se considerar também as mudanças operacionalizadas no mundo do trabalho, que cada vez mais intensamente passa a solicitar outras habilidades e conhecimentos, além daqueles diretamente ligados ao desempenho de uma tarefa.

\section{Algumas considerações finais}

Ao reconstituir historicamente a trajetória da instituição assistencial PROMENOR, e o processo de formação e de cidadania nela instaurado, pode-se dizer que a estruturação dessa obra, ocorrida na década de 70, visava a institucionalização de crianças pobres que faziam da rua seu local de sobrevivência, estando em consonância com a PNBEM (Política de Bem-Estar do Menor) e com o sistema educacional brasileiro, que tinha como meta preparar os individuos para ingressar no mundo do trabalho, implementando cursos profissionalizantes. Desse modo, a complementação escolar, os cursos profissionalizantes implementados e o encaminhamento ao mercado de trabalho demonstram claramente que a instituição possuia um processo de formação, embora não ocupasse o espaço da escola formal. Em face dessas condições, a Instituição recebeu apoio total do governo estadual (1971-1974), da sociedade florianopolitana (1975-1977) e da Irmandade do Divino Espírito Santo (1977 em diante).

A ocupação ordenada do tempo e o encaminhamento ao trabalho foram fatores determinantes na definição desse contexto institucional e na medida que as crianças e adolescentes foram expostos a novas experiências, obtendo com isso 
outros saberes, tornou-se possivel, a instauração de um novo sistema de disposições que resultasse numa mudança de habitus, superando gradativamente os princípios e valores já incorporados. A incorporação do novo habitus deu-se através da relação estabelecida com os demais agentes sociais, uma vez que os usuários eram submetidos aos mesmos condicionamentos e práticas, por possuírem semelhantes condições materiais de existência. Desse modo, é possivel dizer que na PROMENOR o processo de formação é resultante da combinação e da interiorização de inúmeros saberes, os quais ao longo do tempo, se transformaram em disposições gerais, preparando o adolescente para ocupar um lugar no posto de trabalho conferindo-lhe certas competências. Os espaços de autoconstrução foram se ampliando, possibilitando a participação do usuário, tornando-o co-responsável pelo tipo de formação recebida.

A análise mostra que o processo de construção da cidadania, na PROMENOR, acompanhou o momento político e conjuntural vigente no país, bem como os espaços democráticos, sofrendo alterações de acordo com as rupturas contextuais ocorridas. Por conseguinte, a prática profissional do assistente social imposse como uma prática politica e, hoje, pode constituir condição de facilitação para que a cidadania se efetive, na medida que cria e recria práticas democráticas e participativas. Nessa perspectiva Sposatti (1985, p.76) afirma: "reorientar a prática assistencial na direção da luta pela constituição da cidadania implica em ir além do aparente, de modo a fazer emergir a relação particular-universal, a vinculação entre o destino singular vivido e as determinações gerais da classe a que pertence".

Acrescente-se ainda que "a identidade das condições de existência tende a produzir sistemas de disposições semelhantes. Logo, a homogeneidade (relativa) dos habitus está no princípio de uma harmonização objetiva das práticas e das obras". Assim sendo, a prática é o produto da relação dialética entre uma situação e um habitus (Bourdieu, 1983, p. 66).

Desta forma, as disposições gerais (estruturas estruturadas estruturantes) que constituem a formação em instituições assistenciais, operacionalizam-se e são incorporadas através de práticas e ações reguladas e regulares, as quais são asseguradas por um jogo de relações de poder entre os vários agentes envolvidos no processo, e que lutam para impor uma vontade, uma visão de mundo.

Pode-se dizer, então, que embora, as instituições se configurem como um campo de luta, são sobretudo relações, sendo preciso identificá-las, conhecer suas determinações mais amplas e suas significações, tendo em vista que o agir profissional e o estabelecimento de práticas educativas estão diretamente associados ao tipo de relação proposta e implementada entre os agentes.

Portanto, o campo assistencial é influenciado pela dinâmica estrutural dos campos econômico, político e social, logo, pelo campo do poder. Dessa forma, as categorias habitus, campo e poder, teorizadas por Pierre Bourdieu contribuem para o entendimento do processo de formação ocorrido na PROMENOR, atribuindo-lhe cientificidade, quando são empregadas enquanto instrumentais de análise. 


\section{Referências bibliográficas}

BOURDIEU, Pierre. et al. El oficio de sociólogo. Espanha: Siglo Veintiuno, 1978.

O poder simbólico. Rio de Janeiro: DIFEL/BERTRAND, 1989.

. Coisas ditas. São Paulo: Brasiliense, 1990.

. A economia das trocas simbólicas. São Paulo: Perspectiva, 1987.

CHAPOULIE \& BRIAND. “A instituição escolar e a escolarização: uma visão de conjunto". In: Educaçăo \& Sociedade. n. 47, abr. 1994. p. 11-60.

DESAULNIERS, Julieta. B. Ramos. Trabalho: a escola do trabalhador? Porto Alegre: PPGRED/UFRGS, 1993. (Tese doutorado).

. "Formação ou qualificação ou competência". In: Revista Veritas, Porto Alegre: V.38, n. 149, mar. 1993. p. 95-103.

- A instituição: um lugar de produção do social. In: Revista Veritas, Porto Alegre: V. 40, n. 158, jun. 1995. p. 235-242.

- A dinâmica estrutural do campo religioso: alguns dados empíricos. In: Revista Veritas, Porto Alegre: v.41, n. 162 , jun. 1996. p. 249-260

EMPSON. The structure of complex words. Londres, 1969, citado in: TANGUY, Lucie (org.). L'Introuvable relation formation/emploi. Paris: La Documentation Française, 1986.

GROF, Stanislav. Além do cérebro. São Paulo: McGraw-Hill. S.A, 1993.

IAMAMOTTO, Marilda V. Renovação e conservadorismo no serviço social. São Paulo: Cortez, 1992.

ORTIZ, Renato. "A procura de uma sociologia da prática”. In: Pierre Bourdieu. São Paulo: Ática, 1983.

PINTO, Céli. R. J. “O poder e o politico na teoria dos campos”. In: Revista Veritas, Porto Alegre: v. 41, n. 162 , jun. 1996. p. 221-227.

SPOSATTI, Aldaiza Oliveira. et al. Assistência na trajetóna das politicas sociais brasileiras. Uma questão de análise. São Paulo: Cortez, 1986. 